\title{
A Construção do Caso Clínico na Prática Hospitalar: algumas Reflexões Sobre Luto e Toxicomania
}

\author{
Case Report on Hospital Practice: some Considerations \\ About Mourning and Substance Abuse
}

La Construcción del Caso Clínico en la Práctica Hospitalaria: algunas Reflexiones Sobre Luto y Toxicomanía

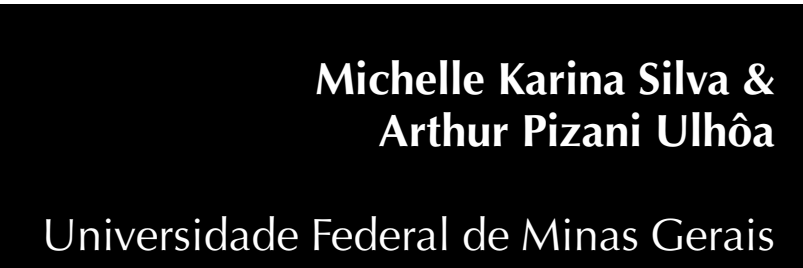

http://dx.doi.org/10.1590/1982-370300292014 
Resumo: O presente trabalho tem o intuito de discorrer sobre alguns aspectos encontrados em um atendimento psicológico de orientação psicanalítica realizado em ambiente hospitalar. Neste sentido, propõe, a partir da construção do caso clínico, uma reflexão acerca do tema da toxicomania, considerando a relação estabelecida com a vivência do luto no caso da paciente atendida. Após uma caracterização do luto a partir do olhar psicanalítico, enfatiza-se o recurso da toxicomania alcoólica em sua associação com o desamparo reeditado pela perda de um objeto amado. Reflete-se, então, sobre a singularidade da solução encontrada pela paciente, pela via do recurso ao entorpecimento narcótico, na lida com o desenlace gradativo provocado por sucessivas perdas em sua história de vida. Discorre-se, neste sentido, sobre como a saída pelo desprendimento da realidade representado pela toxicomania configura-se como uma resposta possível do sujeito frente à perda de referências e ao desamparo advindos da destruição de laços sociais.

Palavras-chave: Toxicomania. Luto. Psicanálise - metodologia. Morte.

Abstract: The aim of this paper is to discuss some features found in psychological counseling that follows a psychoanalytical approach performed in a general hospital. We believe we can reflect on substance abuse and its association with mourning in the present female patient. After characterization of the mourning from a psychoanalytical viewpoint, we emphasize the resource of alcohol addiction in its association with the abandonment arising from the loss of a loved one. We then discuss the singularity of the patient's solution using narcotic torpidity for dealing with the gradual unraveling caused by successive losses in her life. We consider how the choice to withdraw from reality through substance abuse provides a possible answer to the loss of references and to the abandonment caused by the destruction of some specific bonds.

Keywords: Toxicomania. Mourning. Psychoanalysis - methodology. Death.

Resumen: El presente trabajo tiene la intención de articular algunos aspectos encontrados en un atendimiento psicológico, orientado por el psicoanálisis, realizado en el ambiente hospitalar. En ese sentido, propone, bajo la construcción del caso clínico, una reflexión sobre el tema de la toxicomanía, considerando la relación establecida con el luto vivido por la paciente en cuestión. Después de hacer una caracterización del luto embasado en la mirada hacia el psicoanálisis, se enfoca en el recurso de la toxicomanía alcohólica asociada al desamparo reeditado por la pérdida de un objeto estimado. Así, se reflexiona acerca de la singularidad de la solución encontrada por la paciente, por vía del recurso del entorpecimento narcótico, como forma de manejar el desenlace gradual causado por las sucesivas pérdidas en su historia de vida. En ese sentido, se habla sobre cómo la salida por el desprendimiento de la realidad representado por la toxicomanía se plantea como una posible respuesta del sujeto frente a la pérdida de referencias y al desamparo proveniente de la destrucción de los lazos sociales.

Palabras clave: Toxicomania. Luto. Psicoanálisis - metodologia. Muerte.

\section{Introdução}

A clínica com pacientes internados em hospitais tem ganhado importância no cenário de atividades do psicólogo na atualidade. É uma clínica cada vez mais frequente, que obedece às especificidades do ambiente hospitalar e adequa a prática originalmente de consultório a um modelo diferente, caracterizado, entre muitos aspectos, pela menor duração do período de atendimento e pela fragilidade do corpo e do psiquismo do paciente frente à circunstância da internação e o risco de morte.

É sobre um atendimento clínico de orientação psicanalítica realizado em um hospital público de urgência e emergência de Belo Horizonte que versa este trabalho. Serão debatidas questões relativas à toxicomania alcoólica, ponto de fundamental importância nos atendimentos com a paciente, 
passando também pela questão do luto, tema relevante durante todo o processo de acompanhamento psicológico.

Para tanto, faremos uma reflexão acerca da toxicomania a partir de uma retomada da perspectiva de alguns autores da psicanálise, apontando as singularidades da relação mortífera com o álcool a partir da construção do caso clínico, relação essa atravessada por uma sucessão de processos de luto. Retomaremos, também, o clássico "Luto e Melancolia" de Freud para elucidar as questões relativas à dinâmica libidinal envolvida no trabalho do luto, demonstrando como este processo fazia parte do acometimento psíquico da paciente Diana (nome fictício).

\section{A construção do caso clínico}

O caso de Diana foi conduzido com uso da metodologia de construção do caso clínico a partir da prática de supervisão de estágio. Essa metodologia reúne para a psicanálise a dimensão da prática, da pesquisa e da teoria. A partir de um histórico de desenvolvimento desse dispositivo na rede de saúde mental de Minas Gerais (Teixeira, 2010), a construção clínica do caso aponta no ato cotidiano de trabalho das equipes multiprofissionais os efeitos da conversação clínica na direção de tratamento do sofrimento singular do paciente. Além dessa importante qualidade, ela permite a elaboração sobre um corpo discursivo inconsciente estruturado para além do que a escuta do caso permite na dimensão da prática. No campo da saúde mental e da saúde pública presentes no cenário hospitalar, a construção do caso abre espaço na instituição para formação de uma escuta orientada pelos diversos saberes profissionais que se inserem na condução do tratamento do paciente. Nesse sentido, essa metodologia faz eclodir o dizer da equipe e do paciente como produto da escuta do analista, apontando direções e impasses que permitem uma leitura da singularidade e a abordagem da condição subjetiva de sofrimento do sujeito na relação com a instituição (Silva, 2012).

Em articulação com o modelo assistencial de um hospital de urgência e emergência que trabalha com a organização de linhas de cuidado pela definição característica do paciente por perfil nosológico, de faixa etária e de grupo de risco, a psicanálise surge como importante operador clínico. Dentro de uma lógica que faz a estrutura assistencial buscar por um projeto terapêutico elaborado por muitos e que acompanha o paciente em todas as unidades de cuidado do hospital, a psicanálise se comporta como um dispositivo técnico capaz de dar voz aos processos de subjetivação, formando uma base material histórica que garante ao sujeito psíquico um lugar central na direção de tratamento.

Essa experiência de orientação psicanalítica aplicada a um hospital de urgência e emergência - também desenvolvida na pesquisa de mestrado da autora para montagem de um modelo de atuação no campo da pesquisa, da assistência clínica e da supervisão de estágio - permite que se reafirme que "a clínica é ensinamento que se faz no leito, diante do corpo do paciente, com a presença do sujeito" (Viganò, 1999, p. 13). Nesse sentido, a partir da aplicação dessa metodologia, apresentam-se os resultados desse processo por meio da construção do caso clínico, colocando em evidência os efeitos do método como operador clínico de recolhimento da experiência subjetiva na instituição (Silva, 2012).

\section{Apresentação do caso}

A paciente Diana, 54 anos, foi trazida ao hospital pela primeira vez devido a uma crise de hematêmese (expulsão de sangue proveniente do sistema gastro-intestinal pela boca) associada à diarreia escurecida e sangramentos abdominais. Nesta ocasião, foi constatado um comprometimento importante do fígado, associado à hipertensão e ao quadro de ascite (aumento da pressão sanguínea na veia porta, principal veia da região abdominal, normalmente associada ao quadro de cirrose hepática e ao acúmulo de líquidos na cavidade do peritônio), provavelmente decorrentes do etilismo crônico relatado por familiares. A suspeita de leishmaniose visceral foi levantada pela equipe de saúde, tendo sido realizados alguns exames 
e, posteriormente, a liberação da paciente para aguardar em casa os resultados. Neste primeiro momento, o contato da equipe de psicologia com Diana foi rápido: ela foi atendida uma só vez antes de receber alta hospitalar. A demanda, endereçada pelos profissionais da enfermagem, configurou-se pela agitação psicomotora da paciente, bem como pela tentativa de ingerir o álcool etílico utilizado no hospital para a desinfecção.

Aproximadamente um mês após a primeira internação, Diana retornou ao hospital em virtude do resultado positivo da sorologia para leishmaniose visceral, além da cirrose hepática já constatada. A abordagem da equipe de psicologia foi retomada com atendimentos à paciente e aos familiares que duraram cerca de 15 dias, período no qual foram realizados cinco atendimentos com Diana e três com familiares.

Os encontros com a paciente revelaram, além de alguns sintomas corporais, sinais de uma crise de abstinência alcoólica, encefalopatia hepática decorrente do etilismo crônico (piora das funções cerebrais em decorrência do prejuízo da função hepática, isto é, da intoxicação da corrente sanguínea consequente à insuficiência do fígado em remover substâncias tóxicas do corpo) e insuficiência renal aguda possivelmente secundária ao tratamento da leishmaniose--, a presença de um processo de luto desencadeado pela morte recente de uma filha, o que verificamos posteriormente ser resultado de uma sequência de perdas iniciadas cinco anos antes. Segundo relatos dos familiares, o próprio processo de luto estaria intimamente associado à relação destrutiva de Diana com o álcool, conforme veremos posteriormente.

\section{Algumas considerações sobre o luto}

Freud define o luto como um processo econômico ligado à perda de um objeto investido de energia psíquica pelo sujeito, seja este objeto uma pessoa amada, um ideal ou um trabalho que exigiu muito investimento (Freud, 1917/2006).
O luto diante da morte de um ente querido, como relata o autor, é caracterizado por um espírito penoso por parte do paciente, no qual se perde o interesse pelo mundo externo e se recusa qualquer forma de investimento em novos objetos de amor. Assim, a temática do pensamento está voltada quase que exclusivamente para o objeto perdido, ao passo que as funções psíquicas egóicas - a saber, o direcionamento do investimento libidinal para os objetos e atividades, ou motilidadeficam inibidas devido a um retorno da libido para o próprio ego. Isso persiste até que o ego seja capaz de retirar a catexia libidinal do objeto perdido, ficando apto a exercer novamente suas funções.

Escreve Freud acerca dos processos libidinais do luto:

Normalmente, prevalece o respeito
pela realidade, ainda que suas ordens
não possam ser obedecidas de ime-
diato. São executadas pouco a pouco,
com grande dispêndio de tempo e de
energia catexial, prolongando-se psi-
quicamente, nesse meio tempo, a exis-
tência do objeto perdido. Cada uma
das lembranças e expectativas isoladas
através das quais a libido está vinculada
ao objeto é evocada e hipercatexizada,
e o desligamento da libido se realiza
em relação a cada uma delas (Freud,
$1917 / 2006$, p. 250-1).

No caso de Diana é evidente a existência de um processo de luto que decorre da morte recente da filha B. - que ocorreu um mês antes do início dos atendimentos. A temática do discurso da paciente, desde o primeiro encontro, girou exclusivamente em torno desta perda, com relatos permeados de choro e marcados pela depressão do humor. Diana expressava a tristeza advinda da perda da filha, expondo ao estagiário de Psicologia a qualidade da relação entre elas. Segundo ela, tudo fazia lembrar a filha, e por mais que ela tentasse gastar energia pensando em outras coisas, não conseguia desviar o foco dos pensamentos. É bem o que encontramos na descrição freudiana do luto:

Cada uma das lembranças e situações de expectativa que demonstram 
a ligação da libido ao objeto perdido se defrontam com o veredicto da realidade segundo o qual o objeto não mais existe; e o ego, confrontado, por assim dizer, com a questão de saber se partilhará desse destino, é persuadido, pela soma das satisfações narcisistas que deriva de estar vivo, a romper sua ligação com o objeto abolido (Freud, 1917/2006, p. 260).

Assim, vimos, a cada atendimento, repetiremse queixas relativas à tristeza advinda da morte de B., bem como descrições do acidente que a causou, da relação que Diana mantinha com a filha, de suas atividades laborais, seus estudos e de suas características físicas.

Algumas vezes o discurso da paciente se enveredava para a questão da leishmaniose ou para a relação com as outras filhas, o que raramente não era interrompido por alguma lembrança de B. que desencadeasse nova crise de choro e mais relatos sobre ela.

A vivência do luto pela perda da filha é acompanhada de uma reatualização no discurso de perdas anteriores, a saber, a separação do marido, a morte da mãe e a morte de uma irmã. Ainda assim, Diana não cessa de ressaltar que dentre todas as situações semelhantes que já viveu, a atual é de longe a pior.

O luto, portanto, foi questão central nos atendimentos realizados com Diana, sendo a perda da filha o principal conteúdo do discurso da paciente. O que percebemos ao longo da evolução clínica do quadro, porém, foi que havia algo ali que talvez fosse anterior ao luto, algo que era potencializado por um agrupamento de alterações psicopatológicas e de comportamentos que remetiam a uma forma caracteristicamente mortífera de laço com o outro. Assim, chegamos à questão do uso abusivo de álcool.

\section{A relação destrutiva com o álcool}

Desde o início dos atendimentos, era possível perceber os sinais de desorganização mental e comportamental provocados pelo uso abusivo de álcool por parte da paciente, o que foi mais tarde confirmado pelos familiares. Eram claros os sintomas de lentificação psicomotora (alternados com momentos de agitação) e da fala, bem como outros elementos indicativos de um acometimento orgânico provocado pelo uso excessivo de álcool, como transtornos da memória (fabulação e amnésia transitória) e uma confusão mental que oscilava entre um nível leve e moderado. Este último elemento era caracterizado pelas lacunas no discurso e no pensamento, pela desorientação temporal e espacial verificada em alguns momentos, bem como pelas paramnésias, pela sonolência e pelos distúrbios da atenção, a exemplo do que descreve Henry Ey em seu Manual de Psiquiatria (Ey, 1900/1977).

É importante mencionar que o discurso de Diana, tomado pelo tema da morte recente da filha durante os atendimentos, não se estendia por quase nenhum conteúdo além daquele mobilizado pela perda do objeto. O que sabemos, portanto, sobre a relação de Diana com o álcool foi colhido, em sua maioria, em atendimentos com as filhas da paciente, que apontavam para o modo como essa forma de enlaçamento a um objeto específico de satisfação do desejo ganhou contornos mortíferos ao longo do tempo. Segundo as filhas da paciente, há cinco anos - data que coincide com a primeira perda, isto é, a separação do marido - teria ocorrido uma mudança significativa no comportamento de Diana, marcada pela perda da vaidade e do "gosto pela vida" (sic). Se antes a paciente mantinha uma postura de intenso investimento no trabalho, tinha uma preocupação constante com a aparência, mostrava-se empenhada em manter laços afetivos com pessoas do convívio próximo, participando ativamente de um grande número de atividades sociais (eventos festivos, viagens com amigos e familiares), após o divórcio e, mais precisamente após a perda da mãe e da irmã, não mais saia de casa como antes, mantendo uma postura introspectiva e pouco receptiva aos convites que as filhas ou outras figuras próximas endereçavam no intuito de reinseri-la em uma vida ativa.

Diana abandonou o trabalho autônomo, deixando o sustento do lar para as filhas. 
Passava grande parte do tempo em casa dedicando-se a atividades domésticas, em sua maioria, acompanhadas pelo uso, até então moderado, de álcool - ainda que diário. Após a morte de B. em condições fatídicas, contudo, o consumo se tornou mais intenso, aumentando em quantidade e qualidade (a paciente passou a consumir bebidas com teor de álcool mais elevado em doses maiores ao longo de todo o dia, desde o início da manhã). Diana exibia saúde cada vez mais fragilizada. A restrição de suas atividades gerais foi significativa, e a rotina passou a se resumir ao consumo aumentado de álcool. Ainda que as filhas tentassem impedir, a mãe sempre conseguia a bebida, respondendo com hostilidade às proibições e reprovações feitas por elas.

Este laço mortífero com o álcool sustentado por Diana nos faz pensar na solução encontrada pela paciente pela via da toxicomania. Neste sentido, esta se constitui como uma solução que denunciava um posicionamento próprio do sujeito frente à constância dos conflitos intrapsíquicos, associados à dor decorrente das perdas sofridas. Mais precisamente, a solução aqui se relaciona ao ato sintomático que se torna consciente para o sujeito, tamponando representações de ordem inconsciente por via de uma formação de compromisso (Freud, 1896/2006).

É interessante ressaltar que a solução toxicomaníaca, em geral, apresenta-se como um laço de exclusividade que o sujeito empreende com a droga. A exemplo do que aponta Sandra Torossian (2004),

nas toxicomanias temos uma formação sintomática na qual há uma cristalização da posição do sujeito numa relação de exclusividade com a droga. Uma relação que não permite mediações. Há brechas nas quais um terceiro consegue intermediar a relação exclusiva com a droga, mas, geralmente, em algum momento essa intermediação é destituída, voltando, o sujeito, à relação de exclusividade (Torossian, 2004, p.10).

No caso de Diana, contudo, é curioso notar que a solução do sujeito ganha uma particularidade que a distancia, em certa medida, disso que se costuma observar quando se trata uma toxicomania. Ao passo que a maioria dos toxicômanos opta por um afastamento do laço social, a saída pelo etilismo coincidiu, no caso de Diana, com o investimento em um laço específico: aquele sustentado com o objeto perdido, reafirmado no processo de luto. A solução no sentido adotado pela paciente aqui, como formação de compromisso, traz diferenciações do sujeito que se degenera quase que se reduzindo ao usuário dejeto, como indivíduo para ser objeto de consumo, para "fazer-se drogar, fazer-se devorar", etc." (Tarrab, 2004, p. 61), confundido com o próprio objeto. Mas, além disso, Diana aponta em sua experiência para uma posição inconsciente que denuncia um sofrimento psíquico anterior e mais associado ao romance familiar do sujeito em sua conformação subjetiva fundamental.

Antes de passarmos, porém, a uma exposição mais detalhada de nossas construções acerca do caso clínico, é necessário entender um pouco mais algumas peculiaridades da relação do sujeito com a droga. Neste sentido, é possível pensar que, apesar de singular, essa relação comporta elementos universalizáveis relacionados à função deste objeto no circuito pulsional. Segundo Santiago (2001), Freud aponta em sua obra os efeitos da droga no psiquismo, mostrando a prevalência do entorpecimento narcótico sobre os efeitos do recalque e sua capacidade de atuar sobre a economia libidinal do sujeito.

Deste modo, é possível considerar, a partir das teorizações freudianas expostas em $O$ Mal-estar na Civilização, que para dar conta do eterno conflito entre a satisfação das pulsões, guiadas pelo princípio do prazer e o movimento de recalcamento por parte da cultura, como princípio de renúncia às pulsões, a civilização lança mão de alguns mecanismos que visam à diminuição do sofrimento: as técnicas vitais. (Santiago, 2001). É aí que entra a droga, ao lado, por exemplo, da religião e da arte, como uma construção substitutiva que fornece, em sua ação sobre o corpo, um efeito anestesiante, diminuindo o mal-estar do sujeito diante da própria falta. 
Sendo assim, a droga ganha espaço na teoria de Freud como um dispositivo de transformação da economia libidinal. Por meio do uso da droga, o sujeito refugia-se em um mundo interno, livre das pressões da realidade externa. E o faz através daquilo que é próprio a essa técnica vital: a recusa à exigência de renúncia às pulsões imposta pela civilização. No caso de Diana, esta recusa versa sobre a exigência de desligamento da libido do objeto perdido característica do processo de luto. Porém, como a própria construção do caso clínico aponta, este uso não é sem preço, pois a busca da felicidade por meio da droga carrega a nocividade inerente à pulsão de morte (Santiago, 2001).

Mais do que a recusa à renúncia pulsional, o uso da droga acaba sendo uma forma de fugir do encontro com a impossibilidade de completude, advinda da falta estrutural que marca a experiência humana. A droga, ganhando o caráter de um gadget-um produto utilizável que carrega a promessa ilusória da satisfação completa -, interfere na relação pulsional do sujeito com seu corpo, encarnando em seu âmago uma ruptura que empreende uma "separação da droga em relação ao gozo que afeta o sujeito em sua dor de viver." (Santiago, 2001, p. 162). Isto é, por meio do recurso ao objeto droga e à descarga pulsional que ela permite, o sujeito pode se afastar dos sofrimentos inerentes à condição de ser humano. Assim, podemos pensar no laço com a droga como o modo que Diana encontra de se apartar de uma realidade na qual a existência se converte em pura angústia associada ao processo de luto e em desorganizadora ameaça de aniquilamento do próprio eu colocada pelo processo de doença.

É por via dessa complexa teia de experiências de sofrimento (o luto e a grave doença) que podemos perceber, no caso de Diana, a forma como o uso do álcool vai tomando uma mortífera proporção até configurar-se em uma via de existência pela toxicomania. Por meio de uma série de perdas mais ou menos próximas, a começar pela separação do marido, Diana parece ter ficado face a face com a própria falta. Diante desse desamparo, da angústia de confronto com a morte e com a perda, exacerbadas pela morte de B., ela parece ter encontrado a saída pela droga como forma de satisfação e supressão do sofrimento. É possível pensar que, em certa medida, Diana utilizou o recurso da droga para se refugiar em seu próprio mundo, o que a levou àquilo que, em última instância, representaria a característica peculiar da toxicomania: um desenlace cada vez mais pronunciado do sujeito na sua relação com o outro e com a realidade compartilhada.

O que se percebe, contudo, a partir da construção do caso clínico, é que, apesar dessa descrição se aproximar de um quadro toxicomaníaco típico - em que o laço com o objeto droga destroça a relação com o outro -, de uma maneira singular, Diana aponta no endereçamento de sua produção como sujeito falante a recusa em abandonar o objeto perdido: a filha morta há pouco tempo. O laço com o álcool servia, neste momento, como algo que intensificava a dor da perda, afastando o sujeito da realidade ao seu redor na direção de uma vivência cada vez mais intensa do luto. Mas em que medida uma vivência tal como esta serviria como solução para este sujeito?

É interessante, neste sentido, pensar o vínculo estabelecido entre Diana e B. Percebemos que, quando viva, a filha mantinha um laço distinto com a mãe. Ela era a figura que se sacrificava pela paciente, seja deixando de sair para lhe fazer companhia, seja sendo mais dócil que as outras no difícil trato com a mãe etilista. Nesse sentido, é interessante pensarmos que os eventos traumáticos até então relatados - a separação do marido e morte da mãe e da irmã da paciente - comportaram um fator comum de sentimento de abandono vinculado à perda. O sofrimento vivenciado por Diana, o qual ela tentou tratar pelo recurso à droga, ainda era, de certa forma, amenizado pelo laço com esta filha, que se configurava como uma garantia de vínculo frente a todo o desamparo. Porém, após a perda de B., conforme descrevemos, o estado da paciente piorou a ponto de o corpo psíquico já fragilizado ceder lugar, finalmente, aos efeitos devastadores das complicações orgânicas produzidas pelo uso abusivo do álcool. 
O álcool se tornou, então, um objeto único para Diana, cumprindo a função de apartá-la de qualquer contato com outros objetos que a pudessem ameaçar com uma nova perda, ou um novo contato com a angústia real da experiência do vivido. Como consequência disso, fica evidente o retorno do efeito nocivo da pulsão de morte sobre o sujeito, representado pela ausência quase completa de investimento libidinal em outros objetos da realidade que não o álcool, incluindo o descuido pronunciado com o próprio corpo e o abandono do trabalho e dos vínculos com outras pessoas além das filhas vivas. $\mathrm{E}$ isto não pode ser sem efeitos para o corpo do sujeito: ao longo dos cinco anos de uso abusivo de álcool, Diana desenvolveu um quadro crônico de hepatopatia (acometimento crônico do fígado nem sempre de etiologia determinável).

A solução encontrada por Diana comporta, portanto, uma teia singular intrigante. Ao passo que o trabalho do luto pela perda da filha exige um direcionamento da economia libidinal para o objeto perdido, aprisionando a libido em um movimento doloroso de reedição constante desta perda, o apelo ao álcool se interpõe como um laço que permite ao sujeito se apartar da realidade, represando a libido em uma relação que, apesar de mortífera, fornece um distanciamento do sofrimento e do desamparo pela via do entorpecimento do corpo. Além disso, a distância da realidade é uma forma de evitar o sofrimento, posto que elimina qualquer possibilidade de perda na medida em que não há mais laços possíveis.

Neste sentido, temos um duplo movimento de recusa da realidade por parte da paciente: a recusa da perda representada pela peculiaridade do processo de luto e o anestesiamento do corpo como forma de distanciamento da realidade.

Percebemos, assim, que a importância da morte de B., tratada pela paciente como a pior dentre todas as outras perdas relatadas, configurou o agravamento de uma relação já estabelecida com o álcool nos moldes de uma toxicomania. Neste sentido, o apartamento do laço social e a unicidade do objeto tornaram-se ainda mais evidentes, somando-se à presença cada vez maior da pulsão de morte associada à vivência do luto. O investimento no próprio tratamento foi sempre insuficiente durante as internações e a piora clínica da paciente, associada à leishmaniose adquirida, cada vez mais evidente. O resultado dessa piora foi o óbito, constatado pouco menos de um mês após a segunda internação.

Ao longo da condução do caso, os objetivos do suporte oferecido pelos atendimentos psicológicos à paciente se voltaram para os efeitos de suavização do desamparo diante da morte e da entrega do sujeito aos processos desorganizadores da confusão mental aguda. Ainda que diante de um discurso fragmentado, não endereçado e sem grandes possibilidades de elaboração, a escuta analítica sustentava a afirmação do lugar do sujeito no desejo do outro, de sua inserção no universo simbólico, de sua posição de autonomia desejante. Era assim que o tema do luto era o único presente nos atendimentos, mesmo que articulado pela via da produção deliróide confusional característica do funcionamento psíquico nos momentos de terminalidade do corpo. Destarte, o acesso aos conteúdos associados à relação mortífera com o álcool, no intuito de promover qualquer mediação simbólica, era completamente abandonado como plano terapêutico, tendo em vista a condição de fragilidade e desamparo do sujeito ameaçado pela morte e impossibilitado pelos níveis de angústia desse trabalho de elaboração do sintoma. Nesse sentido, a escuta era o operador clínico de esvaziamento do afeto desprazeroso.

Aliado a essa posição de tratamento, o acompanhamento psicológico das filhas da paciente foi ganhando cada vez mais foco, no intuito de conter as angústias advindas do processo de morte da mãe e de oferecer um espaço razoável de acolhimento do sofrimento psíquico no que diz respeito à vivência do luto, visando a torná-lo uma experiência de sofrimento mais razoável para os envolvidos. 


\section{Considerações Finais}

A construção do caso clínico tem se mostrado uma ferramenta essencial para conduta da prática do serviço de Psicologia dentro do hospital de urgência e emergência, principalmente se considerado o tempo limitado para conduta dos casos. Como método de trabalho, esse dispositivo permite a escuta das vozes de muitos (família, equipe de saúde, rede assistencial, gestor institucional) e, sobretudo, do próprio paciente, na construção de uma teia inconsciente que ganha uma materialidade simbólica evidente quando tratada na supervisão clínica de estágio e pela escuta analítica. A exposição da dimensão do Outro enquanto guardião dos registros simbólicos do sujeito na relação com a linguagem, com a cultura e com a alteridade, possibilita uma visão mais aprofundada e, porque não, mais rápida, daquilo que na clínica de consultório muitas vezes só irá se mostrar depois de muitos atendimentos, nos quais o sujeito fala de si e do Outro. Naturalmente, a construção do caso também vai indicar a determinação inconsciente que fixa o sujeito em uma forma de enderaçamento e de relação na transferência e que está muito além do que a Psicologia hospitalar poderia ouvir em uma escuta que foca apenas a relação do sujeito com a doença. Também por isso, a direção de tratamento e a intervenção são calculadas com mais substancialidade e mais elementos, ainda que em um curto tempo. Todos esses fatores que compõem a construção de caso clínico na instituição permitem que se faça uma identificação possível da posição de gozo do sujeito. Além disso, a clínica feita por muitos, evidente na construção do caso clínico, traz em ato a sustentação da ferramenta de trabalho em rede e de forma multidisciplinar tão arduamente defendida pelas políticas públicas de saúde do SUS (Ministério da Saúde, 2010).

Por outro lado, a exposição do caso de Diana nos remete ao fato de que hoje, cada vez mais, a saída pela toxicomania é utilizada para lidar com a impossibilidade estrutural do sujeito falante. Podemos pensar o caso considerando o contexto pós-moderno de excesso de desamparo, marcado pelo imperativo perverso da felicidade e do gozo pleno. Nesse contexto, a utilização da droga, no registro da toxicomania, coloca-se como forma de escapar ao mínimo de desprazer relacionado com alguma aquiescência possível à falta, consentimento imprescindível para a formação de vínculos e do laço social.

No presente caso, a construção de caso clínico coloca uma visão mais clara sobre a escolha do recurso da droga como solução diante de uma sucessão de perdas insuportáveis para o sujeito dentro de um complexo entrelaçamento da dinâmica libidinal da toxicomania e do luto. Algo que coloca o desamparo estrutural do ser diante da experiência de perda e de transbordamento da própria pulsão de morte. Sem desconsiderar, é claro, o importante fato de que essa foi a posição simbólica do sujeito na relação com o Outro até o momento de esgotamento de sua existência.

Uma vez iniciada a relação com a droga, nos termos de uma toxicomania, foi possível ao sujeito fugir do encontro com esse desamparo invariavelmente presente nas relações com a morte. Talvez como forma possível de fugir, portanto, disso que lhe remete à limitação e personifica o mal-estar da civilização já atestado por Freud em suas teorizações.

A relação com a droga na contemporaneidade adquire um caráter muito mais grave devido ao estatuto de gadget que ela ganha, elemento produzido pelo saber científico e utilizado pelo discurso capitalista como promessa de acesso a um gozo pleno. Nesse sentido, talvez os novos tempos apontem para a perda de alguns balizadores, para a supremacia do gozo e para a prevalência da pulsão de morte. Nisso podemos pensar, à esteira das experiências que retiram o sujeito da tradição do pai, para a entrega absoluta a práticas que desprezam a baliza dos ideais que poderiam operar com a função de mediar, de substituir ou de derivar a satisfação pulsional. Considerando essa lógica, é possível identificar a falha de um universalizante da lei, do significante que nomeia o sujeito na esteira da tradição do Pai. Os sintomas do contemporâneo parecem testemunhar a busca 
pela satisfação pulsional direta, sem soluções de compromisso ou metáforas (Machado, 2004). Esses são os sintomas do pânico, da depressão, das toxicomanias, dos transtornos alimentares e tantos outros.

Com a facilidade de aquisição da droga, associado ao desamparo e ao imperativo do gozo característicos da pós-modernidade, fica fácil recorrer a este produto como uma forma de lidar com o mal-estar, o que acaba colocando o sujeito no risco de sucumbir ao efeito nocivo da pulsão de morte.

Os efeitos da intervenção da escuta clínica no caso Diana não são consideráveis dentro de uma realidade na qual há o salvamento do sujeito de sua condição de terminalidade ou de seus modos de relação com o outro produzidos ao longo de sua história.

Dentro da situação clínica aguda dos pacientes em um hospital geral, sobretudo, de paciente com quadro de prognóstico reservado e risco de óbito, como o caso da paciente Diana, as ferramentas de intervenção para elaboração ficam limitadas pela afetação global das funções psíquicas provocadas por quadros toxinfecciosos ou alteração hemodinâmica. Por isso, no caso em questão, a escuta da Psicologia foi inserida como um outro razoável e continente capaz de investir a paciente com representações e elementos de ligação com o universo simbólico do Outro, desestruturado em uma de suas dimensões pela eclosão do real da doença e de sua evolução. O não abandono do lugar de escuta na direção de tratamento com pacientes muito graves, reafirma para equipe e para o próprio sujeito que o movimento de vida precisa ser continuamente reiterado na relação com o outro. A temática deliróide sobre o luto, presente também nas crises confusionais, denunciava a verdade do sofrimento inconsciente do sujeito em um arranjo mental de inconsciência já provocada pelo estado de rebaixamento sensorial inicial. Nesse sentido, é possível dizer mais objetivamente que a direção de tratamento com o sujeito não envolvia a elaboração sobre o sintoma da toxicomania, de um psiquismo anestesiado defensivamente para não ter de se avir com o próprio sofrimento e com o mal-estar que o habitava, mas era sim, a tentativa de não abandonar a paciente ao desamparo desencadeado pelo luto vivido por si e pelo outro.

Naturalmente, no hospital, o envolvimento direto do sofrimento familiar também precisa ser tomado na direção de tratamento. Com as filhas, a escuta caminhava para a tentativa de acomodação simbólica do luto e da realidade sobre essa figura materna, sobre a imagem contraditória e ambivalante desse objeto primordial, tão amado e tão odiado por sua ausência afetiva na relação com o outro após a entrega à toxicomania. Todo esse trabalho permitiu que o sujeito caminhasse ao seu próprio modo para a morte, ao lado de suas filhas que, ainda que de modo ambivalente, sustentaram o investimento amoroso até o final em processo razoável de secretariado amoroso desse percurso.

Finalmente, é possível considerar que no caso de Diana a pulsão de morte operou o seus efeitos de fragilização dos laços do sujeito na experiência de vida antes do processo de adoecimento e morte. Aparentemente, Diana deixou de lutar pela vida, refugiando-se na relação mortífera com o objeto álcool. Como já mencionado, é um caso não muito raro de se deparar nos dias de hoje, e que coloca uma questão importante para a psicanálise: a questão relativa às possibilidades de um tratamento por meio da palavra para aqueles sujeitos que desistiram dela. 


\section{Michelle Karina Silva}

Mestre em Psicologia pela Universidade Federal de Minas Gerais, Belo Horizonte MG. Brasil.

E-mail: michelle.psicologiaufmg@yahoo.com.br

\section{Arthur Pizani Ulhôa}

Graduado em Psicologia pela Universidade Federal de Minas Gerais, Belo HorizonteMG. Brasil.

E-mail: arthur.ulhoa@hrtn.fundep.ufmg.br

\section{Endereço para envio de correspondência:}

Hospital Risoleta Tolentino Neves. Rua Gabirobas nº 01, Laranjeiras. CEP: 31744-012.

Belo Horizonte - MG. Brasil.

Recebido 12/03/2014, Reformulação 29/10/2014, Aprovado 29/01/2015. 
Referências
Ey, H., Bernard, P., \& Brisset, C. (1977). Manual de psiquiatria. Rio de Janeiro: Masson. (Trabalho original publicado em 1900)

Freud, S. (2006). Luto e melancolia. In S. Freud S., Edição standard brasileira das obras psicológicas completas de Sigmund Freud (J. Salomão, trad., Vol. 14, pp. 243-263). Rio de Janeiro: Imago. (Trabalho original publicado em 1917)

Freud, S. (2006) Obserações adicionais sobre as neuropsicoses de defesa. In Freud, S., Edição Standard Brasileira das Obras Psicológicas Completas de Sigmund Freud (J. Salomão, trad., Vol. 3, pp. 157-183). Rio de Janeiro: Imago. (Trabalho original publicado em 1896)

Machado, O. M. R. (2004). Trauma e sintoma na contemporaneidade. In Anais eletrônicos, VII Congresso Brasileiro de Psicopatologia Fundamental. Rio de Janeiro, RJ. Recuperado em 10 de fevereiro de 2014, de http:// ebp.org.br/wp-content/uploads/2012/08/ Ondina_Machado_Trauma_e_sintoma_na_ contemporaneidade1.pdf
Ministério da Saúde, Secretaria de Atenção à Saúde. Política Nacional de Humanização. (2010). Cadernos Humaniza SUS, volume 1: formação e intervenção. Brasília, DF: autor.

Santiago, J. (2001). A droga do toxicômano. Rio de Janeiro: Jorge Zahar.

Silva, M. K. (2012). A feminilidade originária nas psicoses. Dissertação de Mestrado. Faculdade de Filosofia e Ciências Humanas, Universidade Federal de Minas Gerais, Belo Horizonte, MG.

Tarrab, M. (2004). Mais além do consumo: Parte 1 - A maldição do sexo e a época. Revista Curinga, 20, 55-69.

Teixeira, A. M. R. (Org.). (2010). Metodologia em ato. Belo Horizonte, MG: Scriptum.

Torossian, S. D. (2004). De qual cura falamos? Relendo conceitos. Revista da Associação Psicanalítica de Porto Alegre, 25, 9-15.

Viganò, C. (1999). A construção do caso clínico em saúde mental. Revista Curinga, 13, 50-59. 